$$
D O E / 60 / 10561-Q
$$

Rec

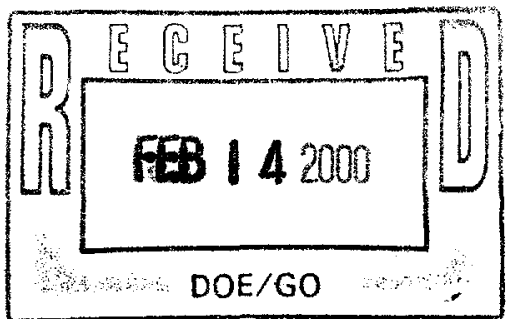

\title{
CATALYTIC MEMBRANE PROGRAM
}

Quarterly Report for the period August 1999 - Oct 1999

Paul K.T. Liu

Project Director

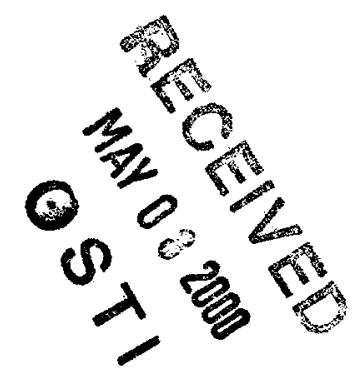

MEDIA AND PROCESS TECHNOLOGY INC.

January 31, 2000

PREPARED FOR THE UNITED STATES

DEPARTMENT OF ENERGY

under Cooperative Agreement

No. DE-FC36-93CH10561 


\section{DISCLAIMER}

This report was prepared as an account of work sponsored by an agency of the United States Government. Neither the United States Government nor any agency thereof, nor any of their employees, make any warranty, express or implied, or assumes any legal liability or responsibility for the accuracy, completeness, or usefulness of any information, apparatus, product, or process disclosed, or represents that its use would not infringe privately owned rights. Reference herein to any specific commercial product, process, or service by trade name, trademark, manufacturer, or otherwise does not necessarily constitute or imply its endorsement, recommendation, or favoring by the United States Government or any agency thereof. The views and opinions of authors expressed herein do not necessarily state or reflect those of the United States Government or any agency thereof. 


\section{DISCLAIMER}

Portions of this document may be illegible in electronic image products. Images are produced from the best available original document. 


\section{SUMMARY OF PROJECT STATUS AND ACTIVITIES PERFORMED}

\subsection{CO2 Membrane Material Development}

The reproducibility study on the synthesis of carbonaceous membrane for $\mathrm{CO} 2$ removal conducted by USC has been successfully completed. In its $4^{\text {th }}$ batch study, a nearly $100 \%$ successful rate was accomplished based upon the criteria of $0.5 \mathrm{M} 3 / \mathrm{M} 2 / \mathrm{hr} / \mathrm{bar}$ of permeance and selectivity of $\mathrm{CO} 2 / \mathrm{CH} 4=10$. Thus far, the USC team has used advanced ceramic substrates for this purpose (see \#1.2). The USC team is currently working on the modification of this protocol for the M\&P low cost ceramic substrate.

\subsection{Use of USC Protocol for M\&P Low Cost Ceramic Substrate}

The current carbonaceous membrane developed by USC requires an advanced quality of ceramic membrane substrate. The USC study concludes that the a small pore size (i.e., 40A), a certain layer thickness (to be determined), and smooth surface topography are essential to prepare a carbon membrane within the porous structure of ceramic substrate. This approach will require a much more expensive substrate, which is not consistent with the primary objective of this program to deliver a low cost ceramic membrane product for gas separations. Presently the USC team is working on the modification of the protocol suitable for the M\&P low cost substrate.

\subsection{Thermal and Hydrothermal Stability Test}

The carbon membrane developed at USC has been subjected to the thermal and hydrothermal stability test at $150 \mathrm{C}$. The membrane shows an excellent stability under this condition. The effect of water on the $\mathrm{CO} 2$ permeance will be investigated in the next quarter.

\subsection{Alternative Carbon Membrane Development}

In parallel with the USC effort, the M\&P team has focused on the deposition of a carbon film on top of its low cost substrate. Presently the M\&P team can fabricate a carbon membrane with a similar permeate flux to the USC's, but with a slightly lower selectivity (i.e,, 5 to 10 ). The M\&P team is currently working on the preparation of this type of membrane for the field test. This type of membranes will be our $1^{\text {st }}$ generation of membrane product for the proposed $\mathrm{CO} 2$ application. The economic analysis performed by GCE has shown the economical viability of this type of membranes. The improvement currently conducted by USC will be the $2^{\text {nd }}$ generation product.

\subsection{Economic Analysis}

A comprehensive analysis on the use of the $\mathrm{CO} 2$ membrane developed from this program for landfill gas recovery has been completed. The analysis shows that a tremendous economic incentive for upgrading the landfill gas to pipeline quality. However, even for power generation using a membrane with a moderate selectivity, a profitable operation can be demonstrated. The results of this analysis have been summarized in a paper presented in the BCC conference. GCE will continue to update the economic analysis when the membrane performance is improved throughout this project..

\subsection{Field Test Preparation}

A meeting with the mountain landfill site at Los Angel was held. This site is selected by our subcontractor, GCE, for the field test due to its proximity to GCE. Presently we are drafting a 
field test plan to be submitted to the site authority for approval. We plan to initiate the design and construction of the field testing unit in this quarter while installing the testing unit in the field in the next quarter. The field test is currently scheduled to begin in the $3^{\text {rd }}$ quarter of this year. The M\&P team will begin the manufacturing development of its low cost ceramic membrane with carbonaceous coating for this field test. In parallel, the USC team will develop its advanced version membrane (with the current expensive substrate) as part of this field test.

\subsection{Presentation}

- GCE presents a paper on the economics of the use of ceramic membranes for recovery of landfill gas at the 1999 BCC Membrane Planning Conference.

- A manuscript has been submitted by the USC team to AIChEJ for consideration of publication. This paper summarizes the morphological study of the carbon membrane developed at USC..

\section{PERCENTAGE COMPLETION OF EACH TASK}

Task 1 membrane Development

Subtask 1.1 Modifying CVD Synthesis Technique Developed on Phase I

Subtask 1.2 Product Optimization Study

Subtask 1.3 Measuring Reproducibility of Membrane Fabrication

Subtask 1.4 Fabrication of Cost-Effective Ceramic

Membrane Modules Developed on Phase I

Task 2

Characterization of Membranes

Subtask 2.1 Functional Performance Evaluation

Subtask 2.2 Thermal, Hydrothermal and Chemical

Stability Evaluation

Task 3

Exploratory Membrane Development

Task 4

Economic Analysis

Task 5

Field Test on Landfill Gas Utilization

Task 6

Interim Technical Report

Task 7

Commercialization

Task 8

Field Demonstration for Natural Gas-related Applications

Task 9

Contaminants Removal from Landfill and 


\section{SIGNIFICANT ACCOMPLISHMENTS EXPECTED IN NEXT QUARTER}

3.1 We will complete the preparation of the membranes for field test. Both M\&P and GCE will complete the design and fabrication of the field test unit.

3.2 The USC team will complete the study on the modification of its existing protocol for deposition of carbon on the M\&P low cost ceramic membrane.

3.3 The USC team will complete the study on the effect of water on the carbon membrane permeance.

3.4 GCE will sign an agreement with a landfill site for conducting the field test.

3.5 M\&P will complete the set-up and preliminary study on the extrusion of the low cost ceramic membrane. A first batch will be produced for the field test.

3.6 GCE will complete the competitive product performance study to benchmark ours vs the existing polymeric and inorganic membranes for similar applications. 